\title{
Phase I trials using Sleeping Beauty to generate CD19-specific CAR T cells
}

\author{
Partow Kebriaei, ${ }^{1}$ Harjeet Singh, ${ }^{2}$ M. Helen Huls, ${ }^{2}$ Matthew J. Figliola, ${ }^{2}$ Roland Bassett, ${ }^{3}$ Simon Olivares, ${ }^{2}$ Bipulendu Jena, ${ }^{2}$ \\ Margaret J. Dawson, ${ }^{2}$ Pappanaicken R. Kumaresan, ${ }^{2}$ Shihuang Su, ${ }^{2}$ Sourindra Maiti, ${ }^{2}$ Jianliang Dai, ${ }^{3}$ Branden Moriarity, ${ }^{4}$ \\ Marie-Andrée Forget, ${ }^{2,5}$ Vladimir Senyukov, ${ }^{2}$ Aaron Orozco, ${ }^{2}$ Tingting Liu, ${ }^{1}$ Jessica McCarty, ${ }^{1}$ Rineka N. Jackson, ${ }^{2}$ Judy S. Moyes, ${ }^{2}$ \\ Gabriela Rondon, ${ }^{1}$ Muzaffar Qazilbash, ${ }^{1}$ Stefan Ciurea, ${ }^{1}$ Amin Alousi, ${ }^{1}$ Yago Nieto, ${ }^{1}$ Katy Rezvani, ${ }^{1}$ David Marin, ${ }^{1}$ Uday Popat, ${ }^{1}$ \\ Chitra Hosing, ${ }^{1}$ Elizabeth J. Shpall, ${ }^{1}$ Hagop Kantarjian, ${ }^{6}$ Michael Keating, ${ }^{6}$ William Wierda, ${ }^{6}$ Kim Anh Do, ${ }^{3}$ David A. Largaespada, ${ }^{4}$ \\ Dean A. Lee, ${ }^{2,7}$ Perry B. Hackett, ${ }^{4}$ Richard E. Champlin, ${ }^{1}$ and Laurence J.N. Cooper ${ }^{2,7}$ \\ 'Department of Stem Cell Transplantation and Cellular Therapy, Division of Cancer Medicine, ${ }^{2}$ Division of Pediatrics, and ${ }^{3}$ Department of Biostatistics, The University of Texas MD Anderson Cancer Center, \\ Houston, Texas, USA. ${ }^{4}$ Center for Cenome Engineering, The University of Minnesota, Minneapolis, Minnesota, USA. ${ }^{5}$ Department of Melanoma and ${ }^{6}$ Department of Leukemia, The University of Texas MD \\ Anderson Cancer Center, Houston, Texas, USA. ${ }^{7}$ The University of Texas Graduate School of Biomedical Sciences, Houston, Texas, USA.
}

BACKGROUND. T cells expressing antigen-specific chimeric antigen receptors (CARs) improve outcomes for CD19-expressing B cell malignancies. We evaluated a human application of T cells that were genetically modified using the Sleeping Beauty (SB) transposon/transposase system to express a CD19-specific CAR.

METHODS. T cells were genetically modified using DNA plasmids from the SB platform to stably express a second-generation CD19-specific CAR and selectively propagated ex vivo with activating and propagating cells (AaPCs) and cytokines. Twenty-six patients with advanced non-Hodgkin lymphoma and acute lymphoblastic leukemia safely underwent hematopoietic stem cell transplantation (HSCT) and infusion of CAR T cells as adjuvant therapy in the autologous $(n=7)$ or allogeneic settings ( $n=19$ ).

RESULTS. SB-mediated genetic transposition and stimulation resulted in 2,200- to 2,500-fold ex vivo expansion of genetically modified T cells, with $84 \%$ CAR expression, and without integration hotspots. Following autologous HSCT, the 30-month progression-free and overall survivals were $83 \%$ and $100 \%$, respectively. After allogeneic HSCT, the respective 12 -month rates were $53 \%$ and $63 \%$. No acute or late toxicities and no exacerbation of graft-versus-host disease were observed. Despite a low antigen burden and unsupportive recipient cytokine environment, CAR T cells persisted for an average of 201 days for autologous recipients and $\mathbf{5 1}$ days for allogeneic recipients.

CONCLUSIONS. CD19-specific CAR T cells generated with SB and AaPC platforms were safe, and may provide additional cancer control as planned infusions after HSCT. These results support further clinical development of this nonviral gene therapy approach.

TRIAL REGISTRATION. Autologous, NCT00968760; allogeneic, NCT01497184; long-term follow-up, NCT01492036.

FUNDING. National Cancer Institute, private foundations, and institutional funds. Please see Acknowledgments for details.

Conflict of interest: The technology described in this report was advanced through research conducted at MD Anderson by L.J.N. Cooper. In January 2015, the technology was licensed by MD Anderson for commercial application to ZIOPHARM Oncology, Inc., and Intrexon Corporation, in exchange for equity interests in each of these companies. L.J.N. Cooper and some co-authors are eligible to receive equity as a result of the licensing of this technology. On May 7, 2015, L.J.N. Cooper was appointed as the Chief Executive Officer at ZIOPHARM. L.J.N. Cooper is also a Visiting Scientist at MD Anderson, where he continues to help supervise the development of this technology. The information being reported in this publication is research in which MD Anderson has an institutional financial conflict of interest. Because MD Anderson is committed to the protection of human subjects and the effective management of its financial conflicts of interest in relation to its research activities, MD Anderson has implemented an Institutional Conflict of Interest Management and Monitoring Plan to manage and monitor the conflict of interest with respect to MD Anderson's conduct of this research.

Submitted: February 1, 2016; Accepted: May 26, 2016.

Reference information: J Clin Invest. 2016;126(9):3363-3376. doi:10.1172/JCI86721.

\section{Introduction}

The adoptive transfer of clinical-grade T cells genetically modified with retrovirus or lentivirus to express a chimeric antigen receptor (CAR) has been shown in clinical trials to lyse $\mathrm{CD} 19^{+}$tumor cells (1-10). Nonviral gene transfer could potentially reduce the costs and complexity associated with recombinant viral vectorbased immunotherapy. Synchronous activation of CAR T cells can cause acute adverse events, especially for patients with a high disease burden (11-13). The issues of cost and cytokine release syndrome may be mitigated by infusing $\mathrm{T}$ cells genetically modified with the Sleeping Beauty (SB) transposon/transposase system to express a CD19-specific CAR after autologous and allogeneic hematopoietic stem cell transplantation (HSCT) to target minimal residual disease (MRD). 
The SB system (14) uses a synthetic DNA transposon for nonviral somatic gene transfer. Genomic incorporation of the CAR transcript from an electrotransferred SB transposon into TA dinucleotide base pairs is enzymatically mediated by an SB transposase (e.g., SB11) (15) coded in trans from another DNA plasmid. The SB transposon was modified to express a second-generation CD19-specific CAR (designated CD19RCD28) $(16,17)$ that activates $\mathrm{T}$ cells through cytoplasmic CD28 and CD3 upon binding cell-surface CD19, independent of HLA (18).

Patients with advanced CD19+ non-Hodgkin lymphoma (NHL) and leukemias undergoing allogeneic HSCT remain at high risk for disease relapse. HSCT can be curative in some patients, with reported 1-year overall survival (OS) rates ranging from less than $20 \%$ to $34 \%$ after reinduction of B-lineage acute lymphoblastic leukemia (ALL) (19-23) and disease progression as the major cause of treatment failure. Recipients of allogeneic HSCT for advanced $\mathrm{CD}^{+}{ }^{+} \mathrm{NHL}$ also have high relapse rates, as patients with chemotherapy-sensitive PET-positive NHL had a 3-year progression rate of approximately $40 \%$ versus $26 \%$ for those who were PET negative (24). No effective conventional treatment options exist for recipients who relapse following HSCT. The OS for adults with ALL who relapse after initial therapy is poor, with less than $10 \%$ 5 -year OS and a median survival of 2-3 months (19, 24-26). To date, the most common relapse-reduction strategy after HSCT involves immune manipulation, ranging from donor lymphocyte infusion (DLI) to second HSCT (27-29). While graft-versus-host disease (GVHD) reduces relapse risk (30), conventional (not genetically modified) DLI provides minimal benefit in these patients, with remission rates below $10 \%$ and a high GVHD incidence $(31,32)$.

CAR T cells have clinical activity against NHL and ALL, but with potentially life-threatening cytokine release syndrome when used in patients with high disease burdens. We hypothesized that CAR T cells might be used more safely in the state of MRD after HSCT while retaining a targeted graft-versus-tumor (GVT) effect. Herein, we report the first human application of the SB system for 26 patients with advanced CD19+ ${ }^{+}$HL or ALL, all of whom safely and successfully received a single administration of patient- or donor-derived CD19-specific CAR T cell infusions in the phase I adjuvant setting following autologous $(n=7)$ or allogeneic $(n=19)$ HSCT. Indeed, the administration of donor-derived CAR T cells also expressing endogenous T cell receptor (TCR) apparently did not exacerbate GVHD. The trials met the primary (safety, feasibility, $\mathrm{T}$ cell persistence) and secondary (efficacy) objectives and these data support the clinical use of SB-modified T cells to improve outcomes of patients with malignancies.

\section{Results}

Integration of CAR after Sleeping Beauty transposition. Highthroughput sequencing was used to examine the CAR integration pattern after $\mathrm{T}$ cells were genetically modified by electrotransfer of 2 SB system DNA plasmids and propagated on $\gamma$-irradiated activating and propagating cells (AaPCs) clone 4 (33) in the presence of soluble recombinant IL-2 and IL-21. Genomic DNA (gDNA) libraries were made from independent polyclonal $\mathrm{T}$ cell populations genetically modified with the SB system to express CD19RCD28, and each integration site was determined in each library. We compared insertions between libraries, assessing for common inser- tional hot spots from separate SB-mediated genetic modifications (Figure 1A). Of 7,436,108 raw reads from 33 independent libraries, $99.9 \%$ of SB integrations were identified, as expected, at TA dinucleotide sites highlighting the lack of illegitimate homologous recombination events. Intragenic insertions represented only $39 \%$ of the total and $96.5 \%$ of these were within introns, while only $3.5 \%$ were within coding (exons) and noncoding ( $5^{\prime}$ UTR and $3^{\prime}$ UTR) regions. Integrations were distributed widely throughout the genome without apparent bias (Figure 1B). One of the largest libraries, C26, shared more than $40 \%$ of its insertional sites with either C12 or C13, and C4 shared many integration sites with C19 (Supplemental Figure 1; supplemental material available online with this article; doi:10.1172/JCI86721DS1), despite all libraries being generated from independent genetic modifications. The majority of libraries had fewer than $20 \%$ of sites shared in common with any other library. Thus, the vast majority of insertion sites were observed only once, arguing against the presence of frequently used, common insertional hot spots.

Manufacturing of genetically modified T cells. To produce CAR $\mathrm{T}$ cells for infusion, peripheral blood (PB) mononuclear cells (PBMCs) simply obtained by venipuncture (Supplemental Table 1), were electroporated with SB transposon and transposase plasmids encoding CD19RCD28 and SB11. Electroporated cells were expanded on $\gamma$-irradiated clone 4 AaPCs for a median of 28 days (autologous: average 29 days, SD 1.4 days; allogeneic: average 28.5 days, SD 3.9 days) with IL-2 and IL-21, enabling selective growth of T cells stably encoding the CD19-specific CAR (Figure 2A), following methods reported previously (34-38). This process resulted in the selective outgrowth of $\mathrm{T}$ cells with integrated CAR (average cell expansion: 2,200-fold autologous and $~ 2,500$-fold allogeneic). Numerically expanded CAR T cells at the time of infusion had, on average, 1 (allogeneic) and 1.3 (autologous) CAR integrants by quantitative PCR (qPCR) (Figure 2B). The majority of manufactured $\mathrm{T}$ cells expressed the CAR and most coexpressed CD8 (Figure 2C and Supplemental Table 2). Expanded T cells were cryopreserved, passed release testing to generate a certificate of analysis (as published) (36), and were thawed on the day of infusion after the recipient met eligibility.

Manufactured T cell products. Our approach to manufacturing was based on the desired outgrowth of a heterogeneous population of $\mathrm{T}$ cells that can sustain proliferation (on AaPCs in the presence of IL-2 and IL-21) mediated by recursive signaling through the introduced CAR. As part of in-process testing, we showed that the karyotypes of the first 5 autologous and 4 allogeneic products (plus 5 additional $\mathrm{T}$ cell products not used in these trials) were normal by G-banding (Supplemental Table 2). The median CAR expression in released $\mathrm{CD}^{+} \mathrm{T}$ cells was $88.5 \%$ (SD 6\%, range 77\%-96\%) and $83 \%$ (SD 6\%, range 59\%-97\%) for patient- and donor-derived $\mathrm{T}$ cells, respectively (Supplemental Table 2). The manufactured products consisted of $\mathrm{T}$ cells with a phenotypic mixture of CCR $7^{\text {neg }}$ CD45RA ${ }^{\text {neg }} C D 27^{+} \mathrm{CD} 28^{+}$differentiated effector memory $\left(\mathrm{T}_{\mathrm{EM}}\right)$, $\mathrm{CCR}^{+} \mathrm{CD} 45 \mathrm{RA}^{+} \mathrm{CD} 27^{+} \mathrm{CD} 28^{+}$naive $\left(\mathrm{T}_{\mathrm{N}}\right)$ or stem cell memory $\mathrm{T}$ cells $\left(\mathrm{T}_{\mathrm{SCM}}\right)$, and $\mathrm{CCR} 7^{+} \mathrm{CD} 45 \mathrm{RA}{ }^{\text {neg }} \mathrm{CD} 27^{+} \mathrm{CD} 28^{+}$central memory $\left(\mathrm{T}_{\mathrm{CM}}\right)$ immunophenotypes (Supplemental Figure 2). No produced $\mathrm{T}$ cells with an exhausted and immune-incompetent phenotype were observed by flow cytometry. However, quantification of mRNA species did reveal that LAG3, PDCD1LG2, and E2F were 
A

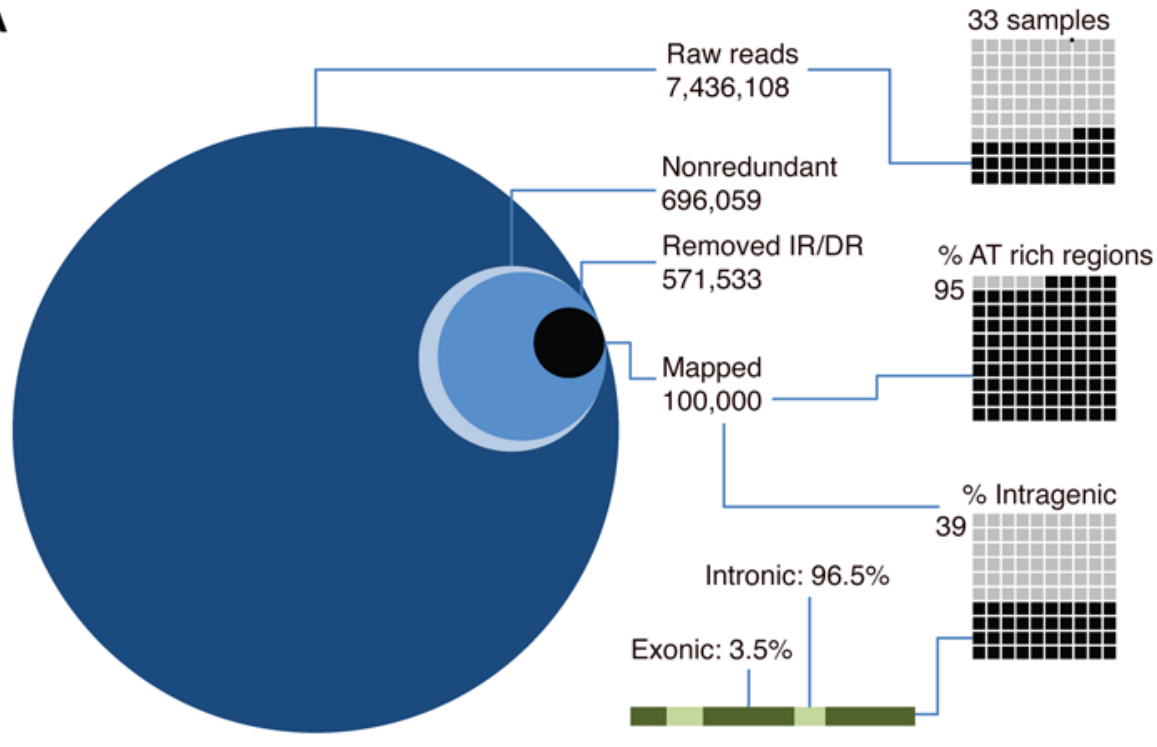

B

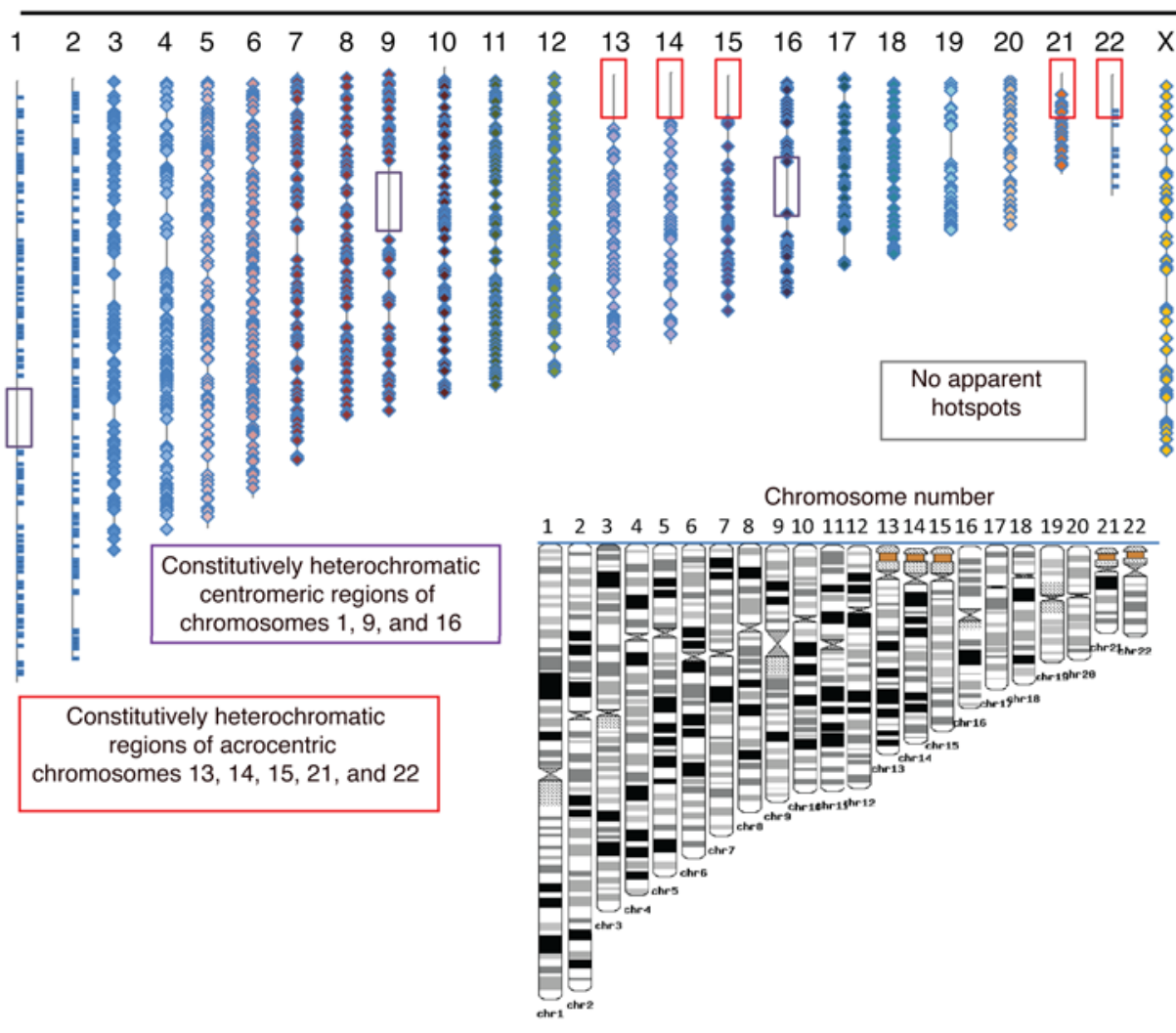

Figure 1. High-throughput sequencing reveals distribution and genomic location of CAR integrants after SB-mediated transposition in primary $T$ cells. (A) The integration site for CAR insertions was determined in genomic DNA libraries $(n=33)$ isolated from independent T cell populations following genetic modification with the SB system and propagation on $\mathrm{AaPCs}$ with cytokines to stably express CD19RCD28 CAR. From greater than 7 million raw sequences, 696,059 nonredundant sequences were obtained. The inverted repeats (IRs) and direct repeats (DRs) were digitally removed, leaving 571,533 unique integrations, of which 100,000 were mapped. The percentages in AT-rich regions and in intragenic regions are displayed in the right-hand graphics. The green bar and associated text display the percentage of intragenic integrations located in introns (light green) vs. exons (dark green). (B) The location of each SB integration (CAR) is mapped onto the 23 human chromosome scaled (as shown in black and white inset) representations. Boxes denote constitutive heterochromatic regions that could not be analyzed. Each integration is noted with a bar (chromosomes 1, 2, and 23) or diamond. Integrations are widely dispersed throughout the genome, without hotspots. increased. Telomere length was not significantly changed over 28 days of ex vivo culture (in fact, there was a trend toward longer telomeres), indicating that CAR $\mathrm{T}$ cells did not enter into replicative senescence (Supplemental Figure 3A), presumably due to IL-21-mediated activation of telomerase via STAT3 (39).

We investigated whether expression of TCR V $\alpha$ and V $\beta$ variants within the CAR $\mathrm{T}$ cell populations changed during culture. Using the direct TCR expression assay (DTEA) (40), we assessed the abundance of $45 \mathrm{TCR} \mathrm{V} \alpha$ and $46 \mathrm{~V} \beta$ genes (www.imgt.org/
IMGTrepertoire) simultaneously in a multiplex digital assay to quantify the TCR transcriptome. Analyses of 5 patient CAR T cell preparations performed before (day 0 ) and 28 days after electroporation demonstrated that a broad TCR V $\alpha$ and $\mathrm{V} \beta$ repertoire was maintained, similar to that present before gene transfer (Supplemental Figure 3, B-D). In addition, CAR T cells from donor P411 underwent an additional cycle of stimulation, and the diversity of the TCR V $\beta$ repertoire (assessed by flow cytometry on day 35) revealed no outgrowth of an oligoclonal T cell population (Supple- 
A
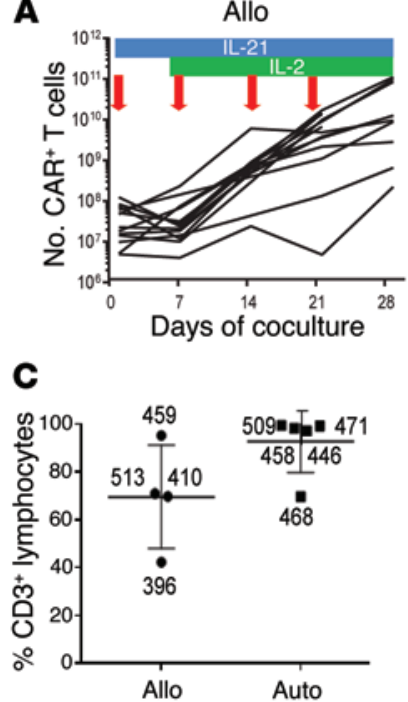
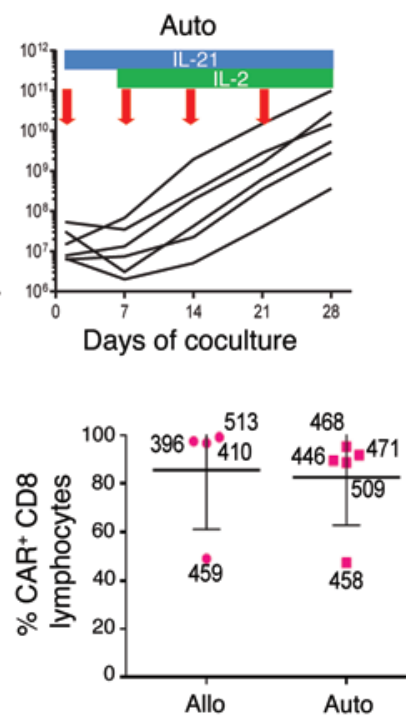

B
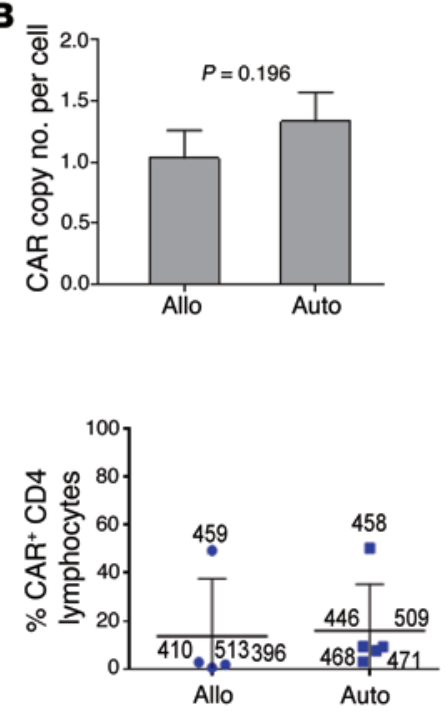

D

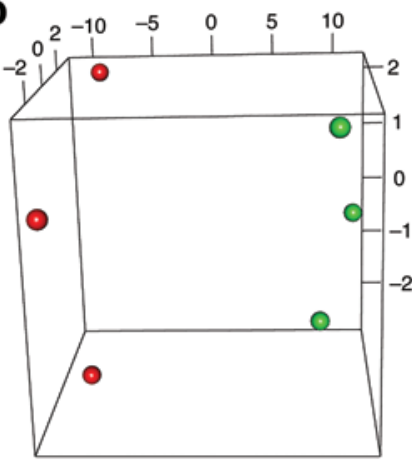

E

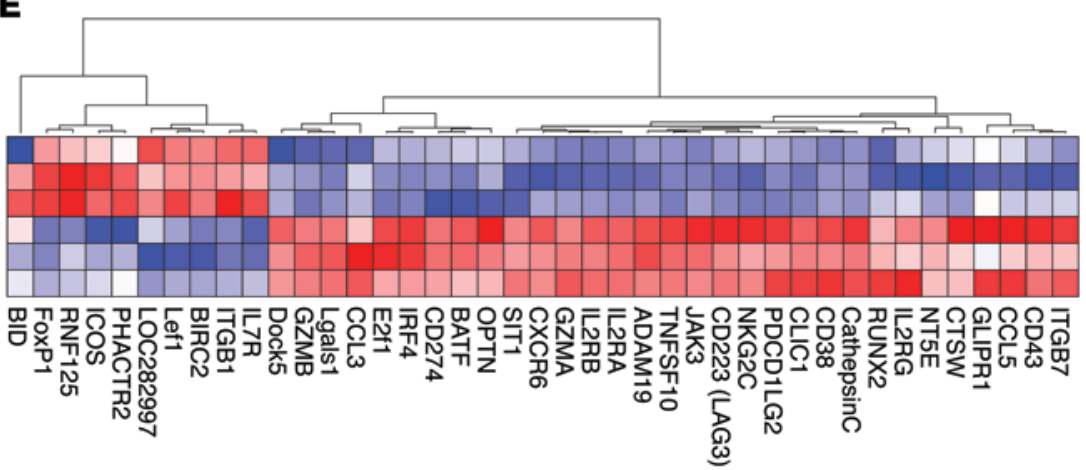

Figure 2. Characterization of genetically modified T cells after electrotransfer of SB plasmids to introduce CAR and coculture on AaPCs with cytokines. (A) Lines represent the numerical expansion of SB-transformed CAR T cells cultured on AaPCs in the presence of cytokines. Blue bars represent exposure to IL-21 in culture, and green bars IL-2. Red arrows indicate the addition of $\gamma$-irradiated AaPCs to the coculture. Allogeneic and autologous samples are presented in the left and right panels, respectively, as labeled. Each line represents a specific study patient sample. (B) Graph represents CAR copy number per cell of genetically modified allogeneic $(n=19)$ and autologous $(n=7)$ CAR T cells for patients by qPCR. Bar, average \pm SD. (C) The plot on the left shows the percentage of modified and expanded lymphocytes expressing CD3 for allogeneic (left side) and autologous (right side) lymphocytes prior to infusion. The heavy line for all similar panels reflects the mean value and the whiskers represent the SD. Numbers beside each marker identify the subject whose data are represented. The percentage of $\mathrm{CD}^{+}$lymphocytes expressing CD8 (middle panel) and CD4 (right panel) is shown. (D) PCA 3D plot of the first 3 principal components of the 41 differentially expressed genes in 6 samples; the first 3 principal components account for approximately $98.1 \%$ of the total variance $(90.5 \%, 4.8 \%$, and $2.8 \%$ ) (red, day 0; green, day 28 ). (E) Cluster analysis of differentially expressed genes by gene pattern is shown, with up- and downregulated genes in culture-day-28 cells compared to unmanipulated culture-day- $0 \mathrm{CD} 3^{+} \mathrm{T}$ cells. Red, highest level of expression; white/pink, moderate level; blue, lowest level of expression.

mental Figure 4). Thus, no significant changes in the TCR repertoire were observed during culture, consistent with random integration after gene transfer (as per Figure 1) followed by unbiased propagation. Measurement of mRNA levels using barcoded digital probes for genes associated with $\mathrm{T}$ cell function (Supplemental Table 3) revealed that $93 \%$ (533 of 574) of genes had unchanged expression in the manufactured products compared with $\mathrm{T}$ cells in PBMCs (autologous $n=1$, allogeneic $n=2$ ). Genes that were significantly different were predominantly those associated with $\mathrm{T}$ cell activation (Figure 2, D and E). These included transcription factors known to be expressed in naive and memory cells (Lef1, FoxP1), integrin ITGB1, and type 1 cytokine receptor $I L 7 R$; costimulatory molecule ICOS; multifunctional protein BIRC2 that regulates not only caspases and apoptosis, but also modulates inflammatory sig- naling and immunity, mitogenic kinase signaling, and cell proliferation; and RNF125, which plays a positive role in TCR-mediated signaling; all of which, as expected, were higher in unmanipulated (day 0) T cells. Effector molecules (GzmA, GzmB, CTSW, inhibitory receptor $N K G 2 C$ ), transcriptional regulators involved in differentiation and proliferation (BATF, OPTN, E2F1, RUNX2), signaling and activation (IL2RA, IL2RB, IL2RG, CD38, JAK3, ADAM19, SIT1, chloride ion channel gene CLIC1, CXCR6), migration and homing (ITGB7, ADAM19, chemokines CCL3 and CCL5), metabolism (GLIPR1), exhaustion-related molecules (LAG3, PDCD1LG2), negative regulators of $\mathrm{T}$ cell function (LGALS1, IRF4), and the senescence-inducing molecule E2F1, were among the genes upregulated in day-28 CAR cells. Gene set enrichment analysis (GSEA) was performed using the Molecular Signature Database 


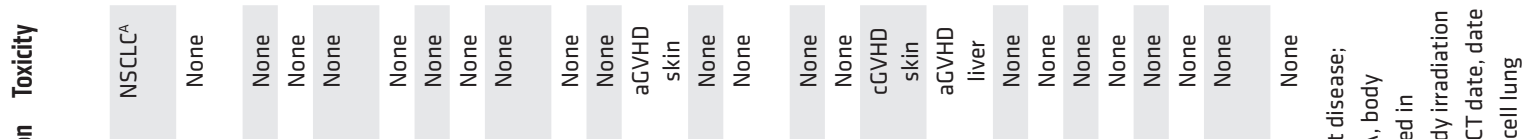

흠

旁蒙

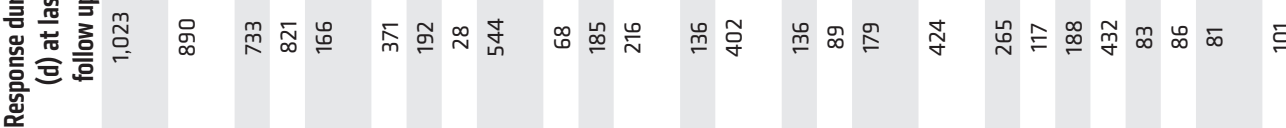

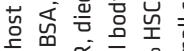

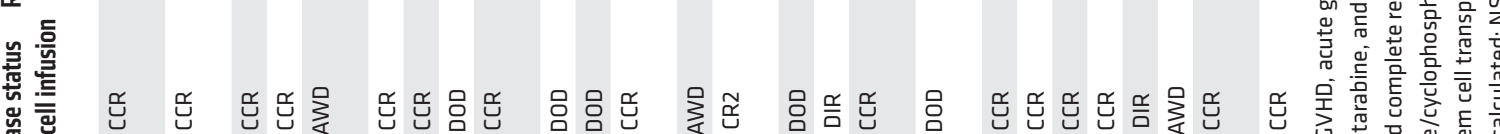

塎

赔

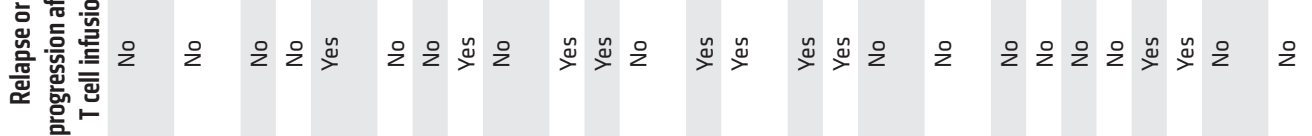
药容

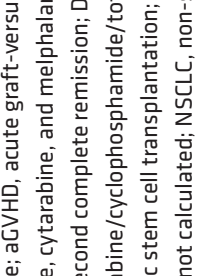

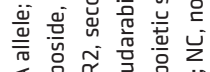

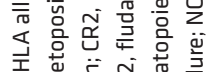

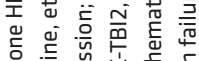

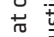

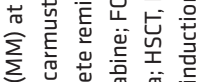

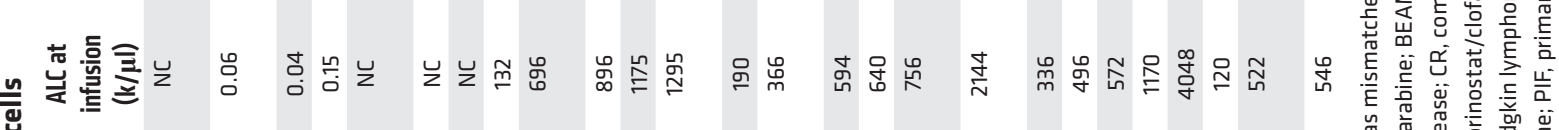

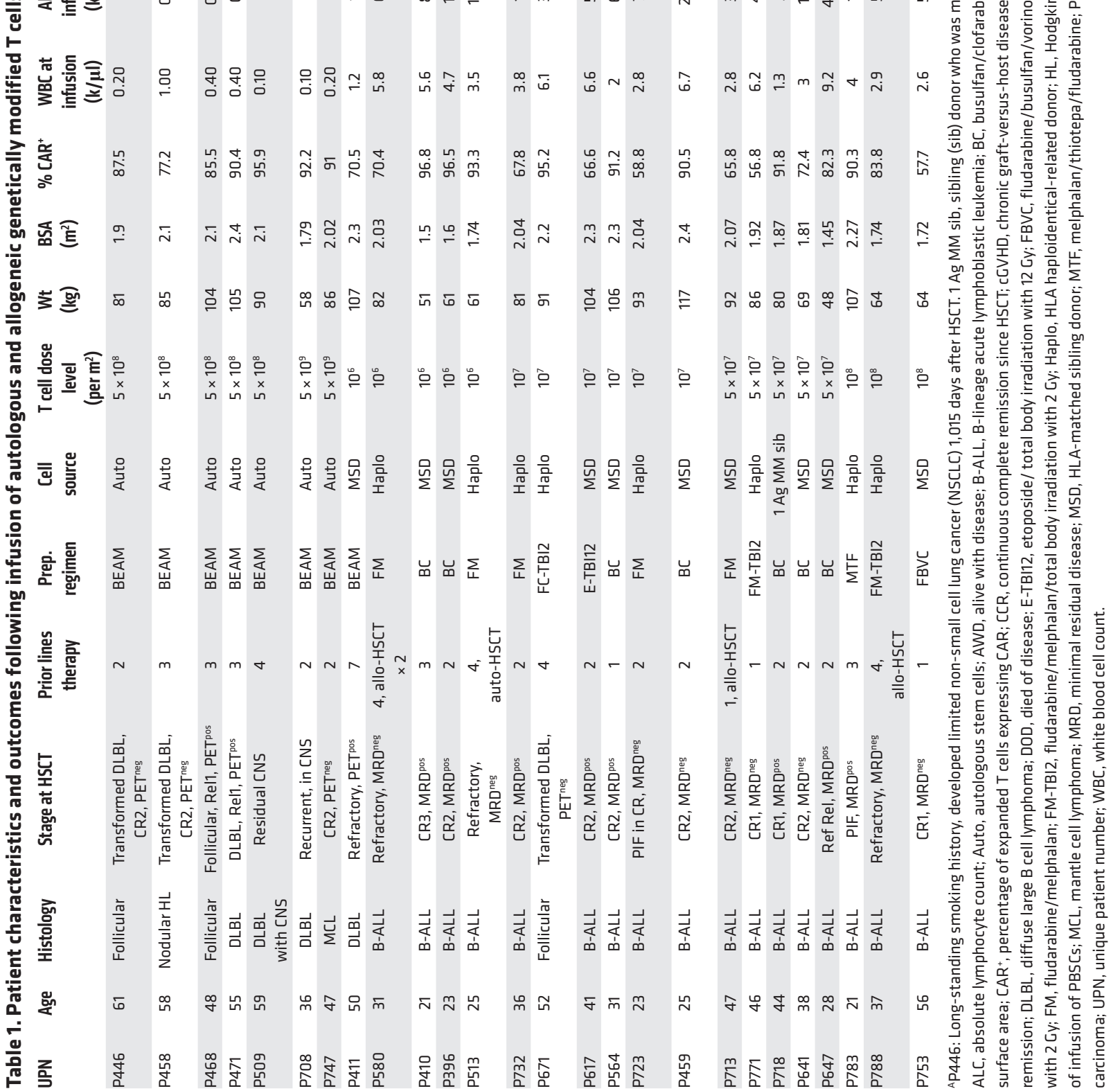


A
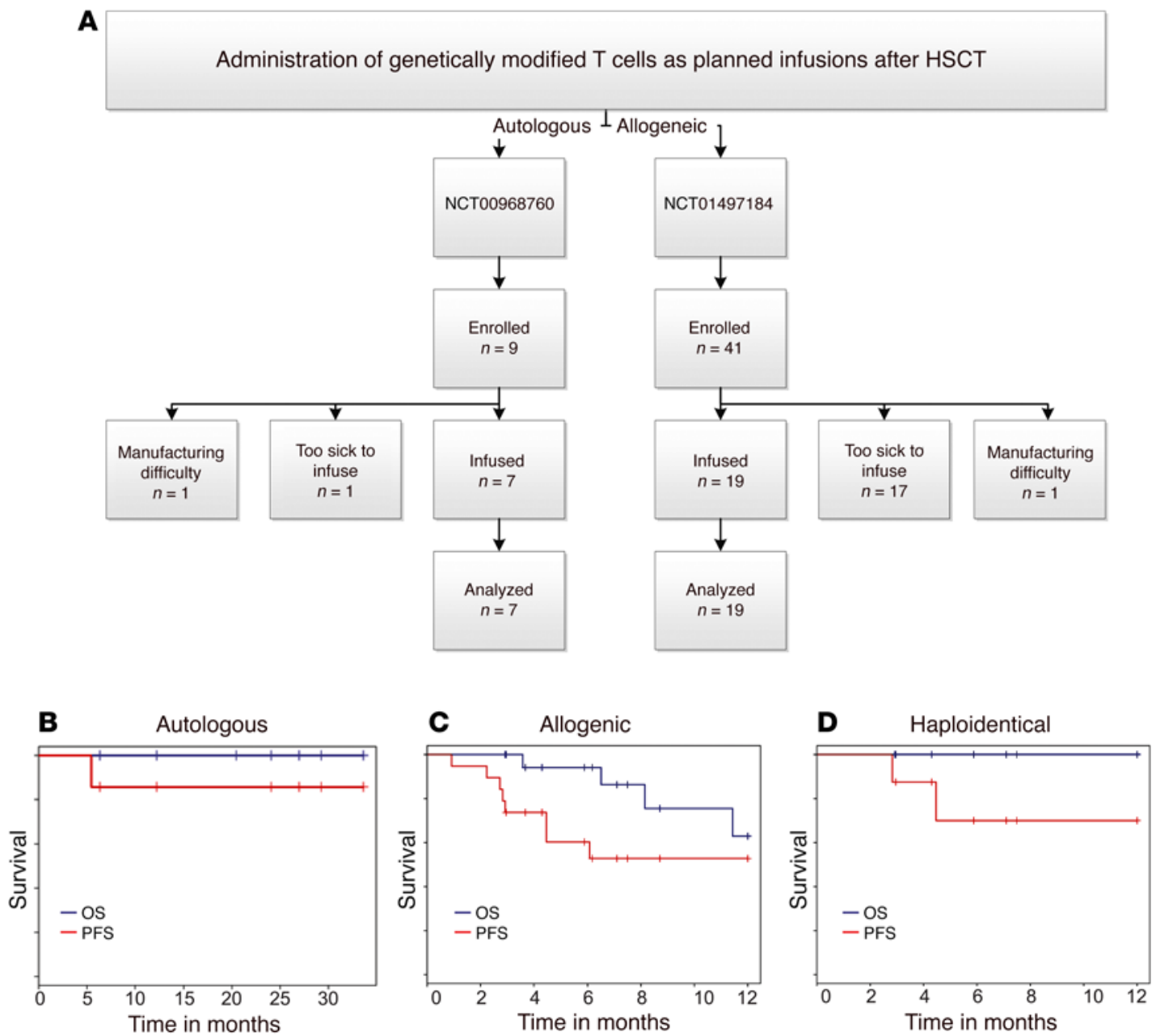

Figure 3. Survival of patients after HSCT after planned infusion of CAR T cells. (A) Flow chart describing numbers of autologous and allogeneic patients enrolled in the 2 trials (NCT00968760 and NCT01497184, respectively). Enrollment occurred to obtain peripheral blood for manufacture of the genetically modified T cells and then the prospective patients were required to meet eligibility to administer the T cells. Some potential recipients were deemed ineligible to receive a successfully manufactured product, which highlights the medical fragility and advanced malignant disease of the enrollees. Some potential recipients were unable to receive T cells due to difficulties associated with their manufacture. All patients who received genetically modified $T$ cells were included in survival analyses. Overall (blue line) and progression-free (red line) survival for (B) autologous as well as (C) allogeneic recipients and (D) the subset of allogeneic recipients from haploidentical donors.

(MSigDB v5.0) on the $\mathrm{C} 2$ and $\mathrm{C} 5$ libraries from Supplemental Figure 1. However, no specific gene set was enriched (FDR $<5 \%$ or $<1 \%$ ) either in day-0 or day-28 cells (data not shown). To avoid transposition after infusion, the presence of SB11 was excluded by PCR at the time of cryopreservation in all infused products (Supplemental Table 2) $(35,38)$. In addition, aliquots of each CAR T cell product were tested for autonomous growth according to our published methods (38), and no aberrant growth was seen (Supplemental Figure 5). As expected, all CAR T cells exhibited significant CD19-specific cytolysis (Supplemental Table 4). These data demonstrate that the electrotransfer of SB plasmids into T cells, and their subsequent numeric expansion on AaPCs with IL-2 and IL-21, results in CAR T cells that are free of detectable SB11, have unaltered TCR diversity and telomere length, and include T cell subpopulation(s) that are predicted to persist after adoptive transfer. Indeed, the electroporation of the SB system and subsequent propagation results in unbiased outgrowth of CAR T cells with
TCR diversity that is similar to PB and phenotypes and genotypes that are consistent with CAR-dependent physiological stimulation of T cells on AaPCs with cytokine support.

Patient characteristics and disease response. We administered thawed CD19-specific patient- or donor-derived T cells into 26 patients with multiply relapsed B-lineage ALL $(n=17)$ or B cell NHL $(n=9)$ on 2 intent-to-treat investigator-initiated clinical trials at the University of Texas MD Anderson Cancer Center (MD Anderson) after autologous ( $n=7$, NCT00968760), or allogeneic non-neonatal ( $n=19$, NCT01497184) HSCT (Table 1). There were an additional 18 prospective patients (36\% of all enrollees) who did not receive their manufactured $\mathrm{T}$ cells due to being ineligible after HSCT, which highlights the medical fragility and advanced state of disease within the cohort. Twelve percent of all enrollees did not receive $\mathrm{T}$ cells due to difficulties during manufacture: inability to grow adequate T cells, $n=1$; contamination of CAR product during manufacture, $n=5$ (Figure $3 \mathrm{~A}$ ). All recipients of $\mathrm{T}$ 

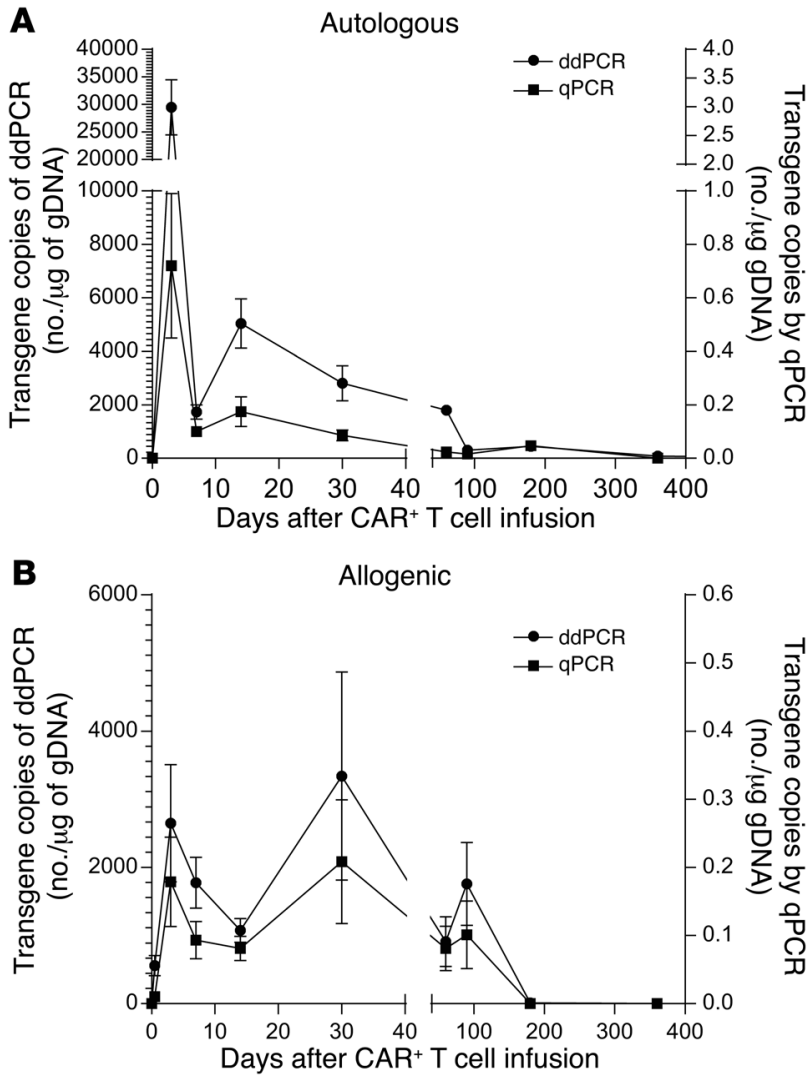

cells were analyzed for survival (Figure 3, B-D). Infusions of CAR $\mathrm{T}$ cells followed an interpatient dose escalation schema based on the number of cryopreserved $\mathrm{CD}^{+} \mathrm{T}$ cells per recipient's calculated body surface area (41) $\left(10^{7} / \mathrm{m}^{2}\right.$ to $5 \times 10^{9} / \mathrm{m}^{2}$ for autologous T cells and $10^{6} / \mathrm{m}^{2}$ to $10^{8} / \mathrm{m}^{2}$ for allogeneic T cells, Table 1$)$.

Seven patients with a median age of 52 years (range 36 to 61 years), including 4 with diffuse large B cell lymphoma (DLBL), were treated with autologous HSCT, conditioned with BEAM (carmustine, etoposide, cytarabine, and melphalan), followed by administration of CAR T cells at an average of 2 days after infusion of PB stem cells (PBSCs). Six of 7 patients remain in complete remission (CR) with a median follow-up of 25.5 months (range: 6.4 to 32.7 months). The patient that did not achieve a CR was transplanted with persistent CNS disease and also received CAR T cells with reduced activation marker expression (Supplemental Figure $2 \mathrm{~F})$. For the autologous HSCT group, the 30-month progressionfree (PFS) and overall survival (OS) rates were $83.3 \%$ and $100 \%$, respectively (Figure 3B).

Nineteen patients (B-ALL, $n=17$; DLBL, $n=2$ ) (Figure 3C) with a median age of 31 years (range 21 to 56 years) received allogeneic CAR T cells. The majority of patients had advanced-stage disease (prior HSCT, $n=3$; CR2, $n=7$; CR3, $n=1$; primary induction failure or refractory relapse, $n=8$ ) at the time of HSCT and T cell infusion. CAR T cells were administered without additional lymphodepletion or other preparation at a median of 64 days (range 43-84 days) following PBSC infusion. The preparative regimen was at the discretion of the treating physician; 11 patients received a myeloablative, mainly busulfan-based regimen, and 8 patients received a fludarabine-based reduced intensity conditioning regimen. GVHD
Figure 4. Sustained persistence of infused genetically modified T cells determined by qPCR and ddPCR in serially collected PBMCs after single infusion of genetically modified T cells. DNA from PBMCs from (A) autologous and (B) allogeneic recipients was tested by qPCR for the presence of CAR sequences. Values at each time point are the average transgene copy number with standard error from all available patient samples at that time point.

prophylaxis consisted of tacrolimus and minidose methotrexate as described for patients after matched-sibling HSCT (42), and tacrolimus, mycophenolate mofetil, and post-HSCT cyclophosphamide after haploidentical HSCT (43). GVHD prophylaxis was tapered and discontinued by 6 months after HSCT, as feasible. Eleven of 19 patients remain in remission with a median follow-up of 7.5 months (range 2.7 to 17.9 months), with 1-year PFS and OS rates of 53\% and $63 \%$, respectively. When the subset of allogeneic patients receiving haploidentical PBSCs were examined, 8 patients had 1-year PFS and OS rates of $75 \%$ and $100 \%$, respectively (Figure 3D). These survival data after allogeneic HSCT also compare favorably with the reported data in the literature (19-24). Furthermore, we demonstrate that up to $10^{8} / \mathrm{m}^{2}$ of CAR T cells can be safely infused after allogeneic HSCT without exacerbating GVHD. These 2 phase I protocols reveal the feasibility of infusing $\mathrm{T}$ cells genetically modified with the SB system. Furthermore, while the primary objectives of these trials were not to establish efficacy, the recipients' survival outcomes are encouraging.

Safety of infusing genetically modified $T$ cells. No unexpected acute infusion or delayed toxicities were noted in the autologous or allogeneic recipients. In the allogeneic trial, 3 patients developed GVHD, which is within expectations. One patient developed grade 1 acute skin GVHD that resolved with topical steroids, 1 patient developed chronic skin GVHD that responded to systemic steroids, and 1 patient with a prior history of drug-induced liver toxicity developed recurrent liver toxicity with a component of liver GVHD 1 month following $\mathrm{T}$ cell infusion, ultimately dying from liver failure. The remaining 5 deaths all were due to disease relapse. No significant infections were noted. In fact, the rate of CMV reactivation in the allogeneic recipients after infusion of genetically modified T cells was only $21 \%(n=4)$ versus $41 \%$ previously reported for our patients without CAR T cell infusion (44). This lower rate of CMV reactivation may be due to the polyclonal nature of the genetically modified product and presence of a subset of $\mathrm{T}$ cells with TCR(s) specific for pathogen(s). Our results are consistent with a favorable safety profile for the administration of autologous and allogeneic CAR T cells after HSCT and fulfill a primary objective of these 2 phase I trials.

Persistence of CAR T cells. CAR T cells were intravenously administered into PB (Supplemental Table 5) at defined times (Supplemental Table 6) after autologous and allogeneic HSCT. The persistence of the infused $\mathrm{T}$ cells in serial PB samples was assessed by both droplet digital PCR (ddPCR) and qPCR using CAR-specific amplimers (Figure 4). CAR T cells could be detected an average of 201 days $(n=7, \mathrm{SD}=118)$ and 51 days $(n=19, \mathrm{SD}=$ 50) after autologous and allogeneic HSCT, respectively (Supplemental Table 7). Within the allogeneic group, 2 recipients had detectable CAR at 90 days, and one of these still had presence of genetically modified $\mathrm{T}$ cells at 1 year. The majority of allogeneic 

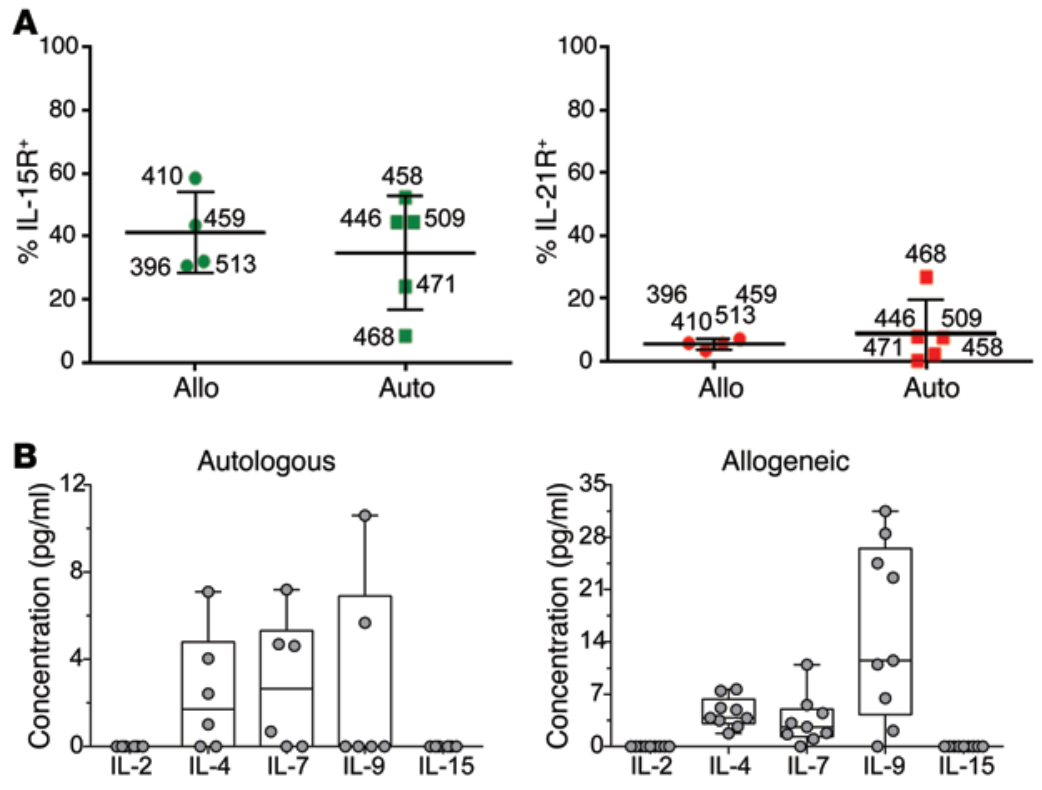

Figure 5. Cytokine milieu at the time of planned T cell infusions. (A) Expression of cytokine receptors on administered T cells. The percentage of expanded CAR T cells expressing IL-15R (left panel) and IL-21R (right panel), determined by flow cytometry, is shown. Data are displayed as per similar panels of Figure 2. (B) Abundance of soluble cytokines that signal through the common cytokine receptor $\gamma$ chain. The box and whiskers plots display the mean levels of each cytokine (pg/ $\mathrm{ml}$ ) in patient sera, while dots reflect the levels from individual patients, 12 hours after single CAR T cell infusions. Data from autologous and allogeneic recipients are shown on the left and right, respectively. recipients tested had measurable CAR expression through day 30 , with expression in most patients declining by 60 to 90 days after administration. There was no apparent positive correlation between $\mathrm{T}$ cell dose and persistence. CAR T cell survival was less in the allogeneic compared with autologous recipients, which may reflect the concomitant use of immunosuppressive medications used to prevent GVHD. On occasion, infused $\mathrm{T}$ cells also could be detected in cerebrospinal fluid and bone marrow (BM) by ddPCR (P564/BM, 3,896 copies/ $\mu$ g gDNA; P580/BM, 49 copies/ $\mu \mathrm{g}$ gDNA; P661/cerebrospinal fluid, 422 copies/ $\mu$ g gDNA). The absolute $T$ cell count on the day of infusion was $38 \pm 59 / \mu$ and $932 \pm$ $954 / \mu \mathrm{l}$ for autologous and allogeneic recipients, respectively (Supplemental Table 5). These data demonstrate that the persistence of the infused $\mathrm{T}$ cells can be sustained after autologous and allogeneic HSCT despite some recipients appearing lymphoreplete, and despite the low levels of $\mathrm{B}$ cells in $\mathrm{PB}$ at the time of T cell infusion in both autologous and allogeneic recipients (Supplemental Table 5 and Supplemental Figure 6).

Cytokine data. The persistence of infused CAR T cells is likely dependent on activation through the CD19RCD28 CAR (to provide signals 1 and 2 through chimeric CD3 $\zeta$ and CD28, respectively) and costimulation through the common cytokine receptor $\gamma$ chain (to provide signal 3) (45). The cryopreserved CAR T cells expressed receptors for IL-15 and IL-21, but expression of other cytokine receptors was below the threshold of detection (Figure $5 \mathrm{~A})$. At the time of infusion the recipients had absent to low circulating levels of IL-2, IL-7, and IL-15, despite the immunosuppressive environments associated with autologous and allogeneic HSCT (Figure 5B and Supplemental Figure 7); thus, the CAR T cells could not apparently benefit from prosurvival signals through the common cytokine receptor $\gamma$ chain.

Reinfusion of CAR T cells and antitumor activity independent of HSCT. Five patients (Supplemental Table 8) with progression of underlying malignancy received a second administration of their prior cryopreserved donor-derived, CD19-specific CAR T cells (the CD19 status of the relapsed B cell malignancies was not tested for these recipients). P396 experienced a BM relapse 3 months following the first CAR T cell infusion, was treated with multiagent chemotherapy, achieved minimal residual disease, and was reinfused with $5 \times 10^{7} / \mathrm{m}^{2}$ CAR T cells under a compassionate need protocol (CIND 12-0067) 6 months following the first infusion. The patient progressed 1 month following the second $\mathrm{T}$ cell infusion with no response to salvage therapy, including blinatumomab, ultimately dying from disease progression. P410 relapsed in the BM 3 months following the first CAR T cell infusion, was reinduced into a fourth CR after multiagent chemotherapy, and received a second CAR T cell infusion of $10^{7} / \mathrm{m}^{2} \mathrm{CAR}$ $\mathrm{T}$ cells under a compassionate need protocol (CIND 12-0060) 4 months following the first infusion. The patient remained in remission for 9 months, then experienced isolated leukemia cutis, eventually succumbing to malignant disease. The trial was then amended to allow for reinfusion of CAR $\mathrm{T}$ cells at the treating physician's discretion, and patients P564, P647, and P671 were reinfused on protocol. P564 had widespread progression of ALL 1 month following infusion of CAR T cells, received further salvage therapy to achieve a third $\mathrm{CR}$, and was reinfused with $10^{7}$ / $\mathrm{m}^{2}$ CAR T cells 3 months after the first administration. The patient subsequently developed liver failure with evidence of GVHD and veno-occlusive disease, and died in CR 3 months after the second CAR T cell infusion. P647 had disease progression 1 month following infusion of CAR T cells, received further salvage therapy, and was reinfused with $5 \times 10^{7} / \mathrm{m}^{2}$ CAR T cells 9 months after the first infusion. The patient died in CR from complications of pneumonia 1 month after this infusion. P671 relapsed 402 days after the initial CAR T cell infusion following a haploidentical HSCT with multiple PET-avid lymph nodes in the right and left axilla, neck, and abdomen. Biopsy revealed recurrent $\mathrm{CD} 19^{+}$follicular lymphoma. The patient was then reinfused with an additional $5 \times 10^{7} / \mathrm{m}^{2}$ CAR T cells without lymphodepleting chemotherapy. Repeat PET 1 month after repeat CAR T cell infusion showed an improvement of the standard uptake value from 13 to 7.9 (Supplemental Figure 8, A and B) and biopsy 2 months after infusion found no evidence 
of lymphoma. One month later he was noted to have increased activity by PET imaging and received a third dose of haploidentical donor-derived CAR T cells (also at $5 \times 10^{7} \mathrm{~T}$ cells $/ \mathrm{m}^{2}$ ), without prior lymphodepleting chemotherapy, and again a reduction in PET activity was observed. P671 experienced no cytokine storm or other adverse events associated with CAR T cell infusions, despite the presence of bulky disease.

\section{Discussion}

We report on 2 phase I clinical trials of a potentially new nonviral approach to the genetic modification of $\mathrm{T}$ cells to express a second-generation CAR. First, we describe what is to our knowledge a first-in-human application of genetic engineering based on SB nonviral gene transfer. When combined with $\gamma$-irradiated AaPCs and exogenous cytokines, the clinical data meet the trials' primary objectives regarding the safety and feasibility of employing this transposon/transposase system to generate CD19-specific CAR T cells for human therapy. Second, we combined the planned administration of CD19-specific CAR T cells after conventional autologous and allogeneic HSCT in efforts to improve the GVT effects and thus decrease the relapse rate of patients with advanced disease. Clinical observations suggest that infused $\mathrm{T}$ cells sustain proliferation in lymphopenic recipients through homeostatic mechanisms, apparently mediated by the removal of regulatory/suppressor cells as well as increased availability of prosurvival cytokines and by attenuation of deleterious immune responses that might otherwise develop against the CAR $(7,46$, 47 ). We note that $10^{8} / \mathrm{m}^{2}$ of CAR allogeneic T cells could be safely infused, including from haploidentical donors, without exacerbating GVHD, which is more than would typically be considered tolerable for administering nongenetically modified DLI (48). The administration of genetically modified T cells in the MRD (adjuvant) setting following HSCT may maximize safety and avoid the potential for cytokine storm that has been reported when $\mathrm{T}$ cells are infused in a high tumor burden setting $(4,8)$. A similar approach recently was advocated to avoid cytokine storm when CD19-specific CAR T cells were used to treat a patient with multiple myeloma (49). This approach reverses the treatment sequence suggested by others $(50)$, in which recipients would initially be infused with tumor-specific CAR T cells, necessitating anticytokine therapy to control toxicities, followed by a standard-of-care HSCT. Furthermore, by using donor-derived CAR T cells in the setting of allogeneic HSCT, we genetically reprogrammed healthy $\mathrm{T}$ cells not previously exposed to chemotherapy. Indeed, there is interest in developing allogeneic CAR T cells (recently reviewed in ref. 51), especially for developing an off-the-shelf product.

We demonstrated that it is safe and feasible to infuse both autologous and allogeneic CAR T cells produced in compliance with cGMP for phase I/II trials. Ex vivo coculture of $\mathrm{T}$ cells on K-562-derived AaPCs with IL-2 and IL-21 was achievable, with no apparent concerns of genotoxicity associated with the use of a transposon and transposase derived from SB and no cytokine storm. This absence of toxicity presumably reflects the low burden of CD19 antigen at the time of CAR T cell infusion. Among our allogeneic HSCT recipients, we did not observe increased rates of infection or GVHD, which stands in contrast with infusion of allogeneic mouse CD19-specific CAR T cells into tumor-bearing mice
(52). Furthermore, only 2 of 10 recipients who underwent HLAmatched sibling donor HSCT and 2 of 9 patients who received haploidentical or mismatched family donor transplants developed reactivation of CMV after receiving CAR T cells. These data compare favorably with our reported CMV reactivation rates of $41 \%$ following matched-sibling (44) and 71\% following haploidentical HSCT (53), suggesting that CAR T cells may help with immune reconstitution. Furthermore, in contrast with the expected rate of $50 \%$ GVHD noted after traditional donor lymphocyte infusion (54), we observed a lower rate of acute GVHD (11\%). These findings are intriguing and suggest that the process of gene transfer and ex vivo CAR-dependent propagation may confer immune tolerance. These safety data are in line with the infusion of donor-derived CD19-specific CAR ${ }^{+}$virus-specific $\mathrm{T}$ cells infused without exacerbating GVHD or inducing cytokine storm after allogeneic HSCT (55). The NCI recently updated their data for infusing donor-derived CAR $\mathrm{T}$ cells for $\mathrm{CD} 19^{+}$malignancies that relapsed after allogeneic HSCT. They noted a response in a quarter of patients treated and no recipient developed new-onset GVHD (56). One possible general criticism of infusing CAR T cells as adjuvant therapy is the cost associated with making a product for potential patients who are unable to receive the therapy due to complications from HSCT. We emphasize that ours was a feasibility, rather than an intention-to-treat, study. However, we do note that $36 \%$ of current enrollees did not receive manufactured $\mathrm{T}$ cells due to adverse events soon after transplant that precluded further therapy with CAR T cells. It is expected that this number will decrease as investigators gain additional experience administering CAR T cells after HSCT.

Efficacy attributable to the administered CAR T cells can be ascertained after HSCT by undertaking a lengthy follow-up of the recipients. The PFS rates for recipients of both autologous and allogeneic HSCT and CAR T cells appeared improved compared with historical data. For patients who received CAR T cells after autologous HSCT, the 30-month PFS rate was approximately $83 \%$ (Figure 3B) compared with a 3-year PFS rate of $49 \%$ reported for patients receiving auto-HSCT for advanced PET-positive DLBL at the time of HSCT (57). We note that 4 of 7 patients in the autologous trial had PET-positive NHL at HSCT, and 3 of these patients cleared their malignant disease with infusions of CAR T cells. The only autologous patient who did not achieve a CR had CNS disease, and that patient's T cells exhibited the lowest expression of HLA-DR and PDL-1 and the highest levels of TIM3 and BTLA (Supplemental Figure 2F), and thus were less active and perhaps less able to eradicate tumor cells. In our allogeneic trial, the 1-year OS was approximately 63\% (Figure 3C), compared with reported 1-year OS rates ranging from less than $20 \%$ to $34 \%$ in this patient population (19-23). Specifically, among our 8 patients receiving haploidentical HSCT for advanced CD19+ ALL, 6 remain in CR, which is especially encouraging for such recipients who have reported relapse rates of $70 \%$ when transplanted beyond second remission (58). Furthermore, the remission of patient P671 following an infusion in the setting of bulky disease provides strong evidence of antitumor activity for the CAR T cells.

Following administration, we were able to detect CAR T cells an average of 201 days in autologous HSCT recipients and 51 days in allogeneic HSCT recipients (Supplemental Table 7). This persis- 
tence is encouraging and compares favorably with that reported in other clinical trials employing a second-generation CAR that signals through chimeric CD28 and CD3- $\zeta(1,2,9,49,59)$, but may be lower than protocols employing a CAR that signals through chimeric CD137 as the source of signal 2, which can last in some cases up to 4 years after infusion (60). The persistence of infused T cells may have been improved by lymphodepletion of the recipient during HSCT conditioning. Indeed, in a study infusing donor-derived CAR T cells following allogeneic HSCT without prior lymphodepletion, in vivo proliferation of the CAR T cells was observed, but the cells apparently did not persist (56). We note that in our study, concurrent administration of tacrolimus for GVHD prophylaxis may have reduced the survival of infused allogeneic $\mathrm{T}$ cells compared with the persistence of autologous $\mathrm{T}$ cells. Consideration of shortened GVHD-prophylaxis approaches or using CD34-selected grafts may provide a better platform for adoptive transfer of CAR T cells.

The CAR T cells in our studies were detected by PCR methods and typically not by flow cytometry. The infused $\mathrm{T}$ cells can receive prosurvival signals through signals 1 and 2 mediated by the CD19RCD28 CAR upon docking with CD19, and presumably receive signal 3 through the common cytokine receptor $\gamma$ chain. However, the recipients of $\mathrm{T}$ cells in our trial had low levels of $\mathrm{B}$ cells at the time of infusion (Supplemental Figure 6) and B cell numbers remained low for several months thereafter, though we did not observe long-term B cell aplasia, a toxicity observed in other CD19-specific CAR T cell trials $(2,7,8)$. Measurements of serum cytokines that signal through the common cytokine receptor $\gamma$ chain revealed absent levels of IL-2 and IL-15, with low to normal levels of IL-4 and IL-7 and normal to elevated IL-9 $(61,62)$. (Figure $5 B)$. Thus, even though the infused CAR T cells could not readily benefit from CAR-dependent as well as cytokine-dependent in vivo signaling, we were still able to detect the sustained persistence of CAR T cells. The combination of low levels of antigendriven stimulation and cytokines is predicted to compromise the persistence of infused T cells. Indeed, as a safety consideration, it was verified that the CAR T cells died upon withdrawal of AaPCs and exogenous cytokine (Supplemental Figure 5). These reduced levels of T cells may have benefited the recipients, as they did not suffer adverse events associated with a cytokine storm stemming from synchronous activation of administered CAR T cells encountering large numbers of $\mathrm{CD}^{+} 9^{+}$cells $(4,8)$. Modifications to the CAR stalk to reduce binding of Fc receptor(s) may further improve the persistence of the genetically modified T cells (63). A followup clinical trial based on the SB system to address these concerns is enrolling at MD Anderson (IND no. 16474). In this protocol we will assess whether CAR T cells infused in the clinical setting of advanced (active) disease will help determine the proliferative capacity of a next-generation CAR design when $\mathrm{T}$ cells encounter an elevated tumor burden.

The human application of the SB system combined with the AaPC propagation platform may help further advancements for $\mathrm{T}$ cell therapy in particular and gene therapy in general $(64,65)$. Nonviral gene transfer has been used previously to genetically modify T cells, with limited clinical success $(47,66,67)$. This was likely due to the inefficiency of gene transfer and resultant need to include immunogenic drug resistance transgenes (66) to select for genetically modified T cells, and the lengthy culturing periods required to retrieve CAR T cells during tissue culture. This difficulty was apparently solved using the SB system, which employs transposition to overcome the low rates of illegitimate recombination to stably integrate plasmid DNA into the T cell genome. An advantage of the SB system is that plasmids can be produced for use in compliance with cGMP for less than the cost of generating clinical-grade recombinant retrovirus or lentivirus (16). Many academic and pharmaceutical companies can produce plasmids for human applications, avoiding the time delay and difficulties associated with reliance upon a small number of manufacturing facilities skilled in producing virus for clinical trials. Furthermore, gene therapy with purified DNA avoids the delay and cost of testing the infusion product for the unwanted presence of replicationcompetent virus. We note that in these studies a transposase of intermediate activity (SB11; ref. 35) was used, rather than the more active SB100X transposase that may direct multiple integrations of transposons into individual cells $(68,69)$. Another advantage of our approach is that we avoided the expense and inconvenience associated with steady-state apheresis, as the electroporation and propagation of $\mathrm{T}$ cells was accomplished from $\mathrm{PB}$ obtained by venipuncture. Thus, the SB system provides a nimble and efficient approach for genetic modification of $\mathrm{T}$ cells, enabling investigators to exchange a transgene or coexpress multiple transgenes to improve therapeutic potential.

In addition to possibly enhancing the GVT effect after HSCT, the human application of CAR T cells to eliminate MRD will have increased importance as this adoptive immunotherapy is applied to patients who have attained remission following alternative therapies and/or if additional infusions of genetically modified $\mathrm{T}$ cells are needed to achieve or sustain complete responses. Indeed, $\mathrm{T}$ cells are among the few agents that appear to completely eliminate cancer cells and thus potentially offer cure to recipients. Furthermore, our finding that large doses of HLA-mismatched CAR $\left(\mathrm{TCR}^{+}\right) \mathrm{T}$ cells can apparently be safely infused provides encouragement for the human application of third-party-derived $\mathrm{T}$ cells as off-the-shelf allogeneic therapy. In summary, the human application of this potentially new approach to gene transfer based on the SB system will enable multiple investigators to advance immunology into immunotherapies for the investigational treatment of human disease.

\section{Methods}

\section{Patient eligibility}

Autologous trial. As published (41), research participants were eligible if they were between 18 and 75 years of age with advanced CD19+ lymphoid malignancies, including NHL, small lymphocytic lymphoma (SLL), chronic lymphocytic leukemia (CLL), diffuse large B cell lymphoma (DLBCL), follicular lymphoma, and mantle cell lymphoma beyond first relapse or primarily refractory to conventional treatment (IRB no. 2007-0635, NIH-OBA no. 0804-922, IND no. 14193, ClinicalTrials.gov Identifier: NCT00968760).

Allogeneic trial. Patients were eligible if they were between 1 and 65 years of age with advanced CD19+ lymphoid malignancies, including NHL, SLL, CLL, follicular lymphoma, mantle cell lymphoma, and ALL (IRB no. 2009-0525, NIH-OBA no. 0910-1003, IND no. 14577, ClinicalTrials.gov Identifier: NCT01497184). Patients were required to have an available HLA-identical donor, HLA 8/8-matched unre- 
lated adult donor, or haploidentical family donor. Additional eligibility criteria for both trials included adequate organ function, a Zubrod performance status of 0-1 or Lansky greater than or equal to $60 \%$, no evidence of uncontrolled infection, and negative serology for hepatitis $B$, hepatitis C, and human immunodeficiency virus. Patients with known allergy to bovine or murine products were excluded. Furthermore, recipients were not allowed to receive systemic corticosteroids within 3 days before, or be experiencing any new clinically significant toxicity within 24 hours before, a T cell infusion. Prospective patients for both trials were referred, recruited, and enrolled at MD Anderson prior to beginning manufacture and then were required to meet eligibility to receive the genetically modified $\mathrm{T}$ cells.

\section{T cell manufacture in compliance with cGMP for phase I/II trials}

Approximately $200 \mathrm{ml}$ of $\mathrm{PB}$ was obtained by venipuncture. The 2 supercoiled SB DNA plasmids (manufactured by Waisman Biomanufacturing, and meeting release criteria) (36) encoding the CAR (CD19RCD28) transposon (16-18) and SB11 transposase $(16,33,38)$, were simultaneously electrotransferred into $2 \times 10^{8} \mathrm{~T}$ cells with a Nucleofector II (Lonza Group). Release criteria to produce banks were as described (36-38). Details of the manufacturing and expansion process are provided in the Supplemental Methods.

\section{Cytolytic activity assessment for CAR T cells}

The specific redirected killing of CAR T cells was evaluated in a standard 4-hour chromium release assay, as described previously (38).

\section{Stem cell procurement}

PBSCs from patients on the autologous trial were collected at MD Anderson after mobilization with filgrastim and chemotherapy. PBSCs were obtained from related allogeneic donors using standard mobilization protocols and apheresis techniques at MD Anderson. The target PBSC dose for both trials was $4 \times 10^{6} \mathrm{CD} 34^{+}$cells $/ \mathrm{kg}$ and the minimal acceptable dose was $2 \times 10^{6} \mathrm{CD} 34^{+}$cells $/ \mathrm{kg}$.

\section{HSCT}

Autologous and allogeneic HSCT was undertaken at MD Anderson (see the Supplemental Methods for the conditioning regimens).

\section{Intravenous infusions of electroporated and propagated T cells}

Autologous trial. $\mathrm{T}$ cells were administered no sooner than 48 hours and no later than 5 days after PBSC infusion.

Allogeneic trial. T cells were administered 6 to 12 weeks following infusion of PBSCs, based on a median time to occurrence of acute GVHD of 6 weeks after HSCT. For details, please see the Supplemental Methods.

\section{Supportive care}

MD Anderson's institutional HSCT guidelines for antimicrobial, antifungal, and antiviral prophylaxis were followed. Patients did not receive filgrastim to enhance neutrophil recovery. Immunoglobulin levels were monitored every 28 days for autologous and allogeneic recipients, and replaced with intravenous immunoglobulin if less than $500 \mathrm{mg} / \mathrm{dl}$.

\section{Study assessments}

Assessments for patients (and healthy donors on the allogeneic trial) included HLA typing, serology for cytomegalovirus (CMV), HIV, human T-lymphotropic virus (HTLV)-1, HCV, and HBV, as well as analysis of $\mathrm{PB}$ collected before manufacture of CAR T cells for protein expression and genetic profiling. Before initiating the HSCT conditioning regimen, the patients were restaged, including BM biopsy and positron emission tomography/computed tomography (PET/CT) scans, as clinically indicated. Immediately after the $\mathrm{T}$ cell infusion (last split dose) weekly for 2 weeks, and at approximately 1, 3, 6, and 12 months, the research participants had physical and laboratory evaluations, such as PB for protein expression and genetic profiling, including PCR analyses for the presence of infused T cells. Skewing of the TCR repertoire may indicate that some infused $\mathrm{T}$ cells can preferentially survive and thus the PB was serially analyzed for emergence of oligoclonal or clonal population(s) of CAR T cells. In addition, PB was obtained to measure cytokine levels. Routine imaging studies and BM aspirate/biopsies were obtained for restaging of disease at 1, 3, 6, and 12 months after infusion of PBSCs. Patients were monitored for 30 days after administration of $\mathrm{T}$ cells to assess possible adverse events. Enrolled research participants who received genetically modified product were required to participate in the long-term follow-up protocol (IRB no. 2006-0676, ClinicalTrials.gov Identifier: NCT01492036) at 1 year after completion of the $\mathrm{T}$ cell protocols per the guidelines set forth by the FDA's Biologic Response Modifiers Advisory Committee that apply to gene transfer studies. Enrollees were assigned a unique patient number to maintain anonymity.

\section{qPCR and ddPCR to measure T cell persistence}

qPCR was performed essentially as previously described (35). Details of the process, including the primers used, are provided in the Supplemental Methods.

\section{PCR to detect the presence of SB11}

Detection of SB11 in genetically manipulated T cells was performed essentially as described previously using primers to detect transposase (Forward: 5'-ATGGGAAAATCAAAAGAAATC-3' and Reverse: 5'-CTAGTATTTGGTAGCATTGC-3') and GAPDH as a loading control (Forward: 5'-TCTCCAGAACATCATCCCTGCCAC-3' and Reverse: 5'-TGGGCCATGAGGTCCACCACCCTG-3') $(16,35,38)$. Detailed methods are available in the supplemental material from ref. 35 .

\section{Linker-mediated PCR (LM-PCR)}

LM-PCR was performed as previously described (70). The primers used for secondary PCR were barcoded and designed for Illumina sequencing; these have been published previously (70). Detailed methods are provided in the Supplemental Methods.

\section{Direct TCR expression analysis to quantify TCR $\mathrm{V} \alpha$ and $\mathrm{V} \beta$ gene expression}

We used DTEA to determine TCR variable $\mathrm{V} \alpha$ and $\mathrm{V} \beta$ gene diversity in T cells before and after electroporation/propagation, essentially as described $(35,40)$. For further information, please see Supplemental Methods.

\section{Multiparameter flow cytometry}

Multiparameter flow cytometric analysis of different cell subsets was performed on banked samples. The reagents for all flow cytometric evaluations are described in detail in the Supplemental Methods. 


\section{Assay for unwanted autonomous growth}

Please see the Supplemental Methods.

\section{Statistics}

The maximal tolerated dose (MTD), defined as the highest $\mathrm{T}$ cell dose at which we were able to treat at least 6 patients with fewer than 2 of 6 patients having a dose-limiting toxicity (DLT), was not reached. DLT was defined as a new adverse event of grade greater than 3 involving cardiopulmonary, gastrointestinal, hepatic (excluding albumin), neurological, or renal toxicity (CTC, version 4) that is probably or definitely related to the infused $\mathrm{T}$ cell products. Patients could be removed from the study for withdrawal of informed consent/authorization, an increasing or unexpected pattern of toxicity deemed unacceptable by the principal investigator, death, noncompliance with study procedures, inability to receive a $\mathrm{T}$ cell infusion, or study completion. The method of Kaplan and Meier (71) was used to estimate the distribution of OS and PFS from the time of transplant. The nanoString gene expression data were initially normalized as suggested by the manufacturer. The normalized data were $\log 2$ transformed and used for analysis. Student's 2-tailed $t$ tests (paired) were used to compare the mRNA levels between day 28 and day 0 for each gene. The raw $P$ values are reported; an average fold change greater than or equal to 2 and a $P$ value less than 0.0171 (false-positive rate $<0.05$ ) was considered statistically significant (multiple comparison adjustment was performed using the Bum method, http://bioinformatics.mdanderson.org/Software/OOMPA/ClassComparison/html/bum.html). Principal component analysis (PCA) was used to check and visualize the similarities and variation among samples using differentially expressed genes. The $\log 2$ transformed data were median centered at the gene level for hierarchical clustering analysis using Euclidean distance by GenePattern v3.9.5 (Broad Institute of Harvard and MIT). GSEA was performed using the differentially expressed gene data by GSEA v2.2.0 (Broad Institute of Harvard and MIT). For TCR V $\alpha$ and TCR V $\beta$ data the Spearman correlation coefficients were calculated to determine similarity and dissimilarity in repertoire between day 0 and ex vivo-expanded day 28. All statistical analyses used SAS 9.3 (SAS Institute) and R version 3.0.2 (R Foundation).

\section{Study approval}

Clinical trials were approved by the MD Anderson IRB. All research participants were provided with written, informed consent prior to study participation at MD Anderson.

\section{Author contributions}

PK, LJNC, and REC designed, and PK led the clinical trial. PK, HS, MHH, MJF, SO, GY, PRK, SS, SM, BM, MAF, VS, AO, DM, and DAL assisted with correlative data. PK helped to write the manuscript. $\mathrm{HS}$ and $\mathrm{MHH}$ assisted with the design of experiments. MHH, MJF, MJD, and EJS assisted with CGMP. RB and GR assisted with ana- lyzing clinical data. SO assisted with molecular biology. JD and KAD assisted with the statistical analyses. TL assisted with collecting clinical data. JMcC and RNJ assisted with regulatory processes. BJ assisted in analysis, compilation of data, and writing of both clinical trials. JSM assisted with writing and the editorial process. MQ, SC, AA, YN, KR, UP, CH, EJS, HK, MK, WW, DAL, and REC collaborated on the clinical trial. DAL provided correlative data. $\mathrm{PBH}$ provided scientific collaboration and the initial SB plasmids. LJNC originated the concept, supervised data analyses, and wrote the manuscript.

\section{Acknowledgments}

We thank the flow cytometry and cellular imaging core facilities at MD Anderson. We thank Pulvarthi Rao (Baylor College of Medicine) for karyotyping and George McNamara (MD Anderson) for editing. The Cancer Center Support Grant core-supported facilities used were Characterized Cell Line Core for fingerprinting of cell lines and GMP facility for generation of $\mathrm{T}$ cell products. This study was funded by Cancer Center Core Grant (CA16672); RO1 (CA124782, CA120956, CA141303, CA141303); P01 (CA148600); SPORES (CA100632, CA136411, CA00632); Albert J Ward Foundation; Alex's Lemonade Stand Foundation; Burroughs Wellcome Fund; Cancer Prevention and Research Institute of Texas; Charles B. Goddard Foundation of Texas; CLL Global Research Foundation; Energy Transfer Partners; Estate of Noelan L. Bibler; Gillson Longenbaugh Foundation; Harry T. Mangurian, Jr., Fund for Leukemia Immunotherapy; Khalifa Bin Zayed Al Nahyan Foundation; Kleberg Foundation; Leukemia and Lymphoma Society; Lymphoma Research Foundation; Miller Foundation; Mr. Herb Simons; Mr. and Mrs. Joe H. Scales; Mr. Thomas Scott; National Foundation for Cancer Research; Pediatric Cancer Research Foundation; Sheikh Khalifa Bin Zayed Al Nahyan Institute for Personalized Cancer Therapy; University of Texas MD Anderson Cancer Center Sister Institution Network Fund and Moon Shot Fund; William Lawrence and Blanche Hughes Children's Foundation. Publication under the Creative Commons CC-BY license is not required.

Address correspondence to: Laurence J.N. Cooper, The University of Texas MD Anderson Cancer Center, Pediatrics, Unit 907, 1515 Holcombe Blvd., Houston, Texas 77030, USA. Phone: 713.563.3208; E-mail: ljncooper@mdanderson.org. Or to: Laurence J.N. Cooper, Ziopharm Oncology, 1 1st Ave \#34 Charlestown, Massachusetts 02129, USA. Phone: 617.259.1987; E-mail: ljncooper@ziopharm.com.

Laurence J.N. Cooper's present address is: Ziopharm, Charlestown, Massachusetts, USA, and is a visiting scientist at The University of Texas MD Anderson Cancer Center, Houston, Texas, USA.

\footnotetext{
1. Brentjens RJ, et al. CD19-targeted T cells rapidly induce molecular remissions in adults with chemotherapy-refractory acute lymphoblastic leukemia. Sci Transl Med. 2013;5(177):177ra38.

2. Davila ML, et al. Efficacy and toxicity management of $19-28 z$ CAR $T$ cell therapy in B cell acute lymphoblastic leukemia. Sci Transl Med.
}

2014;6(224):224ra25.

3. Grupp SA, et al. Chimeric antigen receptor-modified T cells for acute lymphoid leukemia. $N$ Engl $J$ Med. 2013;368(16):1509-1518.

4. Kalos M, et al. T cells with chimeric antigen receptors have potent antitumor effects and can establish memory in patients with advanced leu- kemia. Sci Transl Med. 2011;3(95):95ra73.

5. Kochenderfer JN, et al. B-cell depletion and remissions of malignancy along with cytokineassociated toxicity in a clinical trial of anti-CD19 chimeric-antigen-receptor-transduced $\mathrm{T}$ cells. Blood. 2012;119(12):2709-2720.

6 . Kochenderfer JN, et al. Chemotherapy-refractory 
diffuse large B-cell lymphoma and indolent B-cell malignancies can be effectively treated with autologous $\mathrm{T}$ cells expressing an antiCD19 chimeric antigen receptor. JClin Oncol. 2015;33(6):540-549.

7. Kochenderfer JN, et al. Eradication of B-lineage cells and regression of lymphoma in a patient treated with autologous $T$ cells genetically engineered to recognize CD19. Blood. 2010;116(20):4099-4102.

8. Porter DL, Levine BL, Kalos M, Bagg A, June $\mathrm{CH}$. Chimeric antigen receptor-modified $\mathrm{T}$ cells in chronic lymphoid leukemia. $N$ Engl J Med. 2011;365(8):725-733.

9. Lee DW, et al. $\mathrm{T}$ cells expressing CD19 chimeric antigen receptors for acute lymphoblastic leukaemia in children and young adults: a phase 1 doseescalation trial. Lancet. 2015;385(9967):517-528.

10. Maude SL, et al. Chimeric antigen receptor $T$ cells for sustained remissions in leukemia. $N$ Engl JMed. 2014;371(16):1507-1517.

11. Morgan RA, Yang JC, Kitano M, Dudley ME, Laurencot CM, Rosenberg SA. Case report of a serious adverse event following the administration of $\mathrm{T}$ cells transduced with a chimeric antigen receptor recognizing ERBB2. Mol Ther. 2010;18(4):843-851.

12. Brentjens R, Yeh R, Bernal Y, Riviere I, Sadelain $M$. Treatment of chronic lymphocytic leukemia with genetically targeted autologous $\mathrm{T}$ cells: case report of an unforeseen adverse event in a phase I clinical trial. Mol Ther. 2010;18(4):666-668.

13. Minagawa K, Zhou X, Mineishi S, Di Stasi A. Seatbelts in CAR therapy: How safe are CARS? Pharmaceuticals (Basel). 2015;8(2):230-249.

14. Ivics Z, Hackett PB, Plasterk RH, Izsvák Z. Molecular reconstruction of Sleeping Beauty, a Tc1-like transposon from fish, and its transposition in human cells. Cell. 1997;91(4):501-510.

15. Geurts AM, et al. Gene transfer into genomes of human cells by the sleeping beauty transposon system. Mol Ther. 2003;8(1):108-117.

16. Singh $\mathrm{H}$, et al. Redirecting specificity of T-cell populations for CD19 using the Sleeping Beauty system. Cancer Res. 2008;68(8):2961-2971.

17. Jena B, Dotti G, Cooper LJ. Redirecting T-cell specificity by introducing a tumor-specific chimeric antigen receptor. Blood. 2010;116(7):1035-1044.

18. Kowolik CM, et al. CD28 costimulation provided through a CD19-specific chimeric antigen receptor enhances in vivo persistence and antitumor efficacy of adoptively transferred T cells. Cancer Res. 2006;66(22):10995-11004.

19. Fielding AK, et al. Outcome of 609 adults after relapse of acute lymphoblastic leukemia (ALL); an MRC UKALL12/ECOG 2993 study. Blood. 2007;109(3):944-950.

20. Forman SJ, Rowe JM. The myth of the second remission of acute leukemia in the adult. Blood. 2013;121(7):1077-1082.

21. Kebriaei P, Poon LM. The role of allogeneic hematopoietic stem cell transplantation in the therapy of patients with acute lymphoblastic leukemia. Curr Hematol Malig Rep. 2012;7(2):144-152.

22. Tavernier $\mathrm{E}$, et al. Outcome of treatment after first relapse in adults with acute lymphoblastic leukemia initially treated by the LALA- 94 trial. Leukemia. 2007;21(9):1907-1914.
23. Terwey TH, et al. Allogeneic SCT in refractory or relapsed adult ALL is effective without prior reinduction chemotherapy. Bone Marrow Transplant. 2008;42(12):791-798.

24. Bachanova V, et al. Impact of pretransplantation (18)F-fluorodeoxy glucose-positron emission tomography status on outcomes after allogeneic hematopoietic cell transplantation for non-Hodgkin lymphoma. Biol Blood Marrow Transplant. 2015;21(9):1605-1611.

25. Poon LM, et al. Outcomes of adults with acute lymphoblastic leukemia relapsing after allogeneic hematopoietic stem cell transplantation. Biol Blood Marrow Transplant. 2013;19(7):1059-1064

26. Spyridonidis A, et al. Outcomes and prognostic factors of adults with acute lymphoblastic leukemia who relapse after allogeneic hematopoietic cell transplantation. An analysis on behalf of the Acute Leukemia Working Party of EBMT. Leukemia. 2012;26(6):1211-1217.

27. Balduzzi A, et al. Minimal residual disease before and after transplantation for childhood acute lymphoblastic leukaemia: is there any room for intervention? Br J Haematol. 2014;164(3):396-408

28. Lankester AC, et al. Preemptive alloimmune intervention in high-risk pediatric acute lymphoblastic leukemia patients guided by minimal residual disease level before stem cell transplantation. Leukemia. 2010;24(8):1462-1469.

29. Poon LM, et al. Outcomes of second allogeneic hematopoietic stem cell transplantation for patients with acute lymphoblastic leukemia. Bone Marrow Transplant. 2013;48(5):666-670.

30. Appelbaum FR. Graft versus leukemia (GVL) in the therapy of acute lymphoblastic leukemia (ALL). Leukemia. 1997;11 Suppl 4:S15-S17.

31. Collins RH, et al. Donor leukocyte infusions in 140 patients with relapsed malignancy after allogeneic bone marrow transplantation. JClin Oncol. 1997;15(2):433-444.

32. Passweg JR, et al. Graft-versus-leukemia effects in $\mathrm{T}$ lineage and $\mathrm{B}$ lineage acute lymphoblastic leukemia. Bone Marrow Transplant. 1998;21(2):153-158.

33. Manuri PV, et al. piggyBac transposon/transposase system to generate $\mathrm{CD} 19$-specific $\mathrm{T}$ cells for the treatment of B-lineage malignancies. Hum Gene Ther. 2010;21(4):427-437.

34. Huls MH, et al. Clinical application of Sleeping Beauty artificial antigen presenting cells to genetically modify $\mathrm{T}$ cells from peripheral umbilical cord blood. J Vis Exp. 2013;(72):e50070.

35. Maiti SN, et al. Sleeping beauty system to redirect T-cell specificity for human applications. J Immunother. 2013;36(2):112-123.

36. Singh H, Huls H, Kebriaei P, Cooper LJ. A new approach to gene therapy using Sleeping Beauty to genetically modify clinical-grade T cells to target CD19. Immunol Rev. 2014;257(1):181-190.

37. Singh H, Moyes JS, Huls MH, Cooper LJ. Manufacture of $\mathrm{T}$ cells using the Sleeping Beauty system to enforce expression of a CD19-specific chimeric antigen receptor. Cancer Gene Ther. 2015;22(2):95-100.

38. Singh $\mathrm{H}$, et al. Manufacture of clinical-grade CD19-specific T cells stably expressing chimeric antigen receptor using Sleeping Beauty system and artificial antigen presenting cells. PLOS ONE. 2013;8(5):e64138.

39. Denman CJ, et al. Membrane-bound IL-21 promotes sustained ex vivo proliferation of human natural killer cells. PLOS ONE. 2012;7(1):e30264.

40. Zhang M, et al. A new approach to simultaneously quantify both TCR $\alpha$ - and $\beta$-chain diversity after adoptive immunotherapy. Clin Cancer Res. 2012;18(17):4733-4742.

41. Kebriaei P, et al. Infusing CD19-directed T cells to augment disease control in patients undergoing autologous hematopoietic stem-cell transplantation for advanced B-lymphoid malignancies. Hum Gene Ther. 2012;23(5):444-450.

42. Przepiorka D, et al. Tacrolimus and minidose methotrexate for prevention of acute graft-versus-host disease after matched unrelated donor marrow transplantation. Blood. 1996;88(11):4383-4389.

43. Luznik L, et al. HLA-haploidentical bone marrow transplantation for hematologic malignancies using nonmyeloablative conditioning and highdose, posttransplantation cyclophosphamide. Biol Blood Marrow Transplant. 2008;14(6):641-650.

44. Wilhelm K, et al. The impact of pre-transplant valganciclovir on early cytomegalovirus reactivation after allogeneic hematopoietic stem cell transplantation. JOncol Pharm Pract. 2013;20(4):257-262.

45. Kim MT, Harty JT. Impact of inflammatory cytokines on effector and memory $\mathrm{CD} 8^{+} \mathrm{T}$ cells. Front Immunol. 2014;5:295.

46. Miller JS, et al. Successful adoptive transfer and in vivo expansion of human haploidentical NK cells in patients with cancer. Blood. 2005;105(8):3051-3057.

47. Till BG, et al. Adoptive immunotherapy for indolent non-Hodgkin lymphoma and mantle cell lymphoma using genetically modified autologous CD20specific T cells. Blood. 2008;112(6):2261-2271.

48. Lewalle $\mathrm{P}$, et al. Donor lymphocyte infusions in adult haploidentical transplant: a dose finding study. Bone Marrow Transplant. 2003;31(1):39-44.

49. Garfall AL, et al. Chimeric antigen receptor $\mathrm{T}$ cells against CD19 for multiple myeloma. $N$ Engl JMed. 2015;373(11):1040-1047.

50. Nellan A, Lee DW. Paving the road ahead for CD19 CAR T-cell therapy. Curr Opin Hematol. 2015;22(6):516-520.

51. Yang Y, Jacoby E, Fry TJ. Challenges and opportunities of allogeneic donor-derived CAR T cells. Curr Opin Hematol. 2015;22(6):509-515.

52. Jacoby E, Yang Y, Qin H, Chien CD, Kochenderfer JN, Fry TJ. Murine allogeneic CD19 CAR T cells harbor potent antileukemic activity but have the potential to mediate lethal GVHD. Blood. 2016;127(10):1361-1370.

53. Di Stasi A, et al. Similar transplantation outcomes for acute myeloid leukemia and myelodysplastic syndrome patients with haploidentical versus 10/10 human leukocyte antigen-matched unrelated and related donors. Biol Blood Marrow Transplant. 2014;20(12):1975-1981.

54. Martin PJ, et al. First- and second-line systemic treatment of acute graft-versus-host disease: recommendations of the American Society of Blood and Marrow Transplantation. Biol Blood Marrow Transplant. 2012;18(8):1150-1163.

55. Cruz CR, et al. Infusion of donor-derived 


\section{CLINICAL MEDICINE}

CD19-redirected virus-specific T cells for B-cell malignancies relapsed after allogeneic stem cell transplant: a phase 1 study. Blood. 2013;122(17):2965-2973.

56. Brudno JN, et al. Allogeneic T cells that express an anti-CD19 chimeric antigen receptor induce remissions of B-cell malignancies that progress after allogeneic hematopoietic stem-cell transplantation without causing graft-versus-host disease. J Clin Oncol. 2016;34(10):1112-1121.

57. Sauter CS, et al. Prognostic value of FDG-PET prior to autologous stem cell transplantation for relapsed and refractory diffuse large B-cell lymphoma. Blood. 2015;125(16):2579-2581.

58. Symons HJ, et al. Haploidentical BMT using fully myeloablative conditioning, $\mathrm{T}$ cell replete bone marrow grafts, and post-transplant cyclophosphamide (PT/Cy) has limited toxicity and promising efficacy in largest reported experience with high risk hematologic malignancies. Biol Blood Marrow Transplant. 2015;21(2):S29.

59. Savoldo B, et al. CD28 costimulation improves expansion and persistence of chimeric antigen receptor-modified $\mathrm{T}$ cells in lymphoma patients. JClin Invest. 2011;121(5):1822-1826.
60. Porter DL, et al. Chimeric antigen receptor $\mathrm{T}$ cells persist and induce sustained remissions in relapsed refractory chronic lymphocytic leukemia. Sci Transl Med. 2015;7(303):303ra139.

61. Kim HO, Kim HS, Youn JC, Shin EC, Park S. Serum cytokine profiles in healthy young and elderly population assessed using multiplexed bead-based immunoassays. J Transl Med. 2011;9:113.

62. Kleiner G, Marcuzzi A, Zanin V, Monasta L, Zauli G. Cytokine levels in the serum of healthy subjects. Mediators Inflamm. 2013;2013:434010.

63. Jonnalagadda $\mathrm{M}$, et al. Chimeric antigen receptors with mutated IgG4 Fc spacer avoid fc receptor binding and improve $T$ cell persistence and antitumor efficacy. Mol Ther. 2015;23(4):757-768.

64. Hackett PB, Largaespada DA, Switzer KC, Cooper LJ. Evaluating risks of insertional mutagenesis by DNA transposons in gene therapy. Transl Res. 2013;161(4):265-283.

65. Izsvák Z, Hackett PB, Cooper LJ, Ivics Z. Translating Sleeping Beauty transposition into cellular therapies: victories and challenges. Bioessays. 2010;32(9):756-767.

66. Jensen MC, et al. Antitransgene rejection responses contribute to attenuated persistence
The Journal of Clinical Investigation

of adoptively transferred CD20/CD19-specific chimeric antigen receptor redirected $\mathrm{T}$ cells in humans. Biol Blood Marrow Transplant. 2010;16(9):1245-1256.

67. Till BG, et al. CD2O-specific adoptive immunotherapy for lymphoma using a chimeric antigen receptor with both $\mathrm{CD} 28$ and 4-1BB domains: pilot clinical trial results. Blood. 2012;119(17):3940-3950.

68. Huang X, et al. Stable gene transfer and expression in human primary $\mathrm{T}$ cells by the Sleeping Beauty transposon system. Blood. 2006;107(2):483-491.

69. Mátés L, et al. Molecular evolution of a novel hyperactive Sleeping Beauty transposase enables robust stable gene transfer in vertebrates. Nat Genet. 2009;41(6):753-761.

70. Rahrmann EP, et al. Forward genetic screen for malignant peripheral nerve sheath tumor formation identifies new genes and pathways driving tumorigenesis. Nat Genet. 2013;45(7):756-766.

71. Dinse GE, Lagakos SW. Nonparametric estimation of lifetime and disease onset distributions from incomplete observations. Biometrics. 1982;38(4):921-932. 